IRSTI 61.59 .35

\title{
Simulation of mechanical strain of metallic electron-irradiated polyimide films
}

\author{
A.D. Muradov ${ }^{1 *}$, A. Młyniec ${ }^{2}$, K.M. Mukashev', \\ G.Sh. Yar-Mukhamedova ${ }^{1}$ and Y.Y. Sandybaev ${ }^{1}$ \\ ${ }^{1}$ Al-Farabi Kazakh National University, Almaty, 050040 Kazakhstan \\ ${ }^{2}$ Stanistawa Staszica Academy of Mining and Metallurgy, Kraków, Poland \\ *e-mail: abyl.muradov@mail.ru
}

\begin{abstract}
The impact of silver metallization and electron irradiation on the physical and mechanical properties of polyimide films has been studied. The metal that impregnated the structure of the polyimide substrate was $1-5 \mu \mathrm{m}$. The surface coatings contained $80-97 \%$ of the relative silver mirror in the visible and infrared regions. Irradiation was performed at the ELU-6 linear accelerator with an average beam electron energy of $2 \mathrm{MeV}$, an integral current of up to $1000 \mu \mathrm{A}$, a pulse repetition rate of $200 \mathrm{~Hz}$, and a pulse duration of $5 \mu$ s. The absorbed dose in the samples was 10, 20,30, and 40 MGy. The samples were deformed at room temperature under uniaxial tension on an Instron 5982 universal testing system. A substantial growth of mechanical characteristics resulting from the film metallization, as compared to the pure film, was observed. The growth of the ultimate strength by $\Delta \sigma=105 \mathrm{MPa}$ and the plasticity by $\Delta \varepsilon=75 \%$ is connected with the characteristics of the change of structure of the metallized films and the chemical etching conditions. The electron irradiation of the metallized polyimide film worsens its elastic and strength characteristics due to the formation of new phases in the form of silver oxide in the coating. The concentration of these phases increased with increasing dose, which was also the result of the violation of the ordered material structure, namely, the rupture of polyimide macromolecule bonds and the formation of new phases of silver in the coating. A mathematical model agrees with the experimental data.
\end{abstract}

Keywords: polyimide, composite materials, metallization, deformation, electron irradiation, modulus of elasticity, Young's modulus, mathematical model.

PACS number(s): 51.50.+v;51.10.+y;52.80.Dy;52.25.Fi.

\section{Introduction}

Preparation and study of the metallized polymeric materials [1-4] caused by their extensive use in industry [5], electronics [6,7], as well as in production of consumer goods [8]. Main directions of new materials search lies in obtaining composite films with different thickness metallic phase distribution retaining mechanical properties $[9,10]$. The most promising variants among metallized polymeric materials are polyimides [11-13] along with their high thermal stability, good dielectric properties and low coefficient of expansion [14-17].

On the one hand, crucial moment in such studies is to identify the influence of a metallized coating type, its structure and nature on mechanical properties of the polymer composite material. On the other hand it is important to obtain constitutive equations of viscoelastic media to describe a particular type of mechanical loading, that allows to predict the performance of the material in various types of loading (static, dynamic, etc.) [18-20].

Therefore, the study of viscoelastic, strength and other mechanical properties of the metallized polymeric materials, revealing the influence of the structure of the coating on their mechanical behavior, the development of their behavior forecasting methods seems now as urgent and as important task .

\section{Research technique}

Metallized polyimide films of the thickness $\mathrm{d}=35$ $\mathrm{mm}$, obtained at the Institute of Chemical Sciences NAS RK named after Bekturov, were discovered. The first stage of the process chain comprised by obtaining polyimide different thicknesses films on the basis ABimid varnish. Technological scheme involves rolling out the varnish through spinnerets to 
conveyor belt cohesive layer, followed by drying at $90^{\circ} \mathrm{C}$ and the thermal cyclization at $180^{\circ} \mathrm{C}$ for 1 and 2 hours, respectively to film rolls sizes.

The second technological scheme of obtaining roll of metallized film lies in successive processing of polyimide film original in an organic solvent, an aqueous-alcoholic alkaline solution, washing, chelation by recovering metal, washing with dialysis and thermo - chemical recover of a metal at $220^{\circ} \mathrm{C}$.

The metallized polyimide films were made as a continuous ( two- or one-sided ) metallic layer impregnated into the structure of the polyimide substrate. The metal phase is made of a silver of thickness of 1 to 5 microns. The overall thickness was about 25-100 micrometers depending on the initial film thickness.

Metallized coatings surface contained $80 \div 97$ $\%$ of relative silver mirror in the visible and infrared regions. Their surface resistance varied in the range of $0.1 \div 10$ ohms depending on the thickness of the metal layer and metal nature. The temperature dependency took the form of $\rho s=0.98\left(1+2,65 \cdot 10^{-3 t}\right)$ in the range from $-25^{\circ} \mathrm{C}$ up to $+200{ }^{\circ} \mathrm{C}$.

There was no sign of detachment (delamination) of the metal surface layer until the destruction of the entire polymer layer integrity at loads of at least 160 $\operatorname{MPa}\left(200^{\circ} \mathrm{C}\right)$.

Number of samples of 25-100 microns thick, 5 $\mathrm{mm}$ wide and $70 \mathrm{~mm}$ (working length $50 \mathrm{~mm}$ ) length were cut from the resulting roll of metallized PI film, which are then were divided into 5 groups for further electron irradiation of various doses. One group of samples was taken as control variant, and was not irradiated.

Irradiation of samples was performed on a linear accelerator ELU-4. The average energy of the electron beam was $2 \mathrm{MeV}$, integral current up to 1000 $\mathrm{mA}$, sending pulse frequency of $200 \mathrm{~Hz}$, pulses duration of $5 \mathrm{~ms}$. Absorbed dose (D) of each group of samples was respectively 10, 20, 30 and $40 \mathrm{MGy}$.

After that, the samples were deformed at room temperature in a uniaxial stretching mode using universal testing machine Instron 5982. The mechanical tests methodology was based on the use of universal testing machine Instron 5982 and Bluehill 3 software, which is designed to determine the mechanical characteristics of various materials. In Bluehill 3 test method selection is the basis of the experiment, which is assigned to the desired type of static testing. Testing was based on the GOST 25.604-82 and American standard ACTM D3039 / D 3039M - 00.

Technical characteristics of the electromechanical machine Instron 5982: maximum load of $100 \mathrm{kN}$, load measurement accuracy and deformation of $+/-$ $0.5 \%$ of measured value.
The study of the structural changes of produced composite materials as a result of the effects of physical factors mentioned above were produced in the $\mathrm{X}$-ray difraktrometre of DRON-2M type in air at a temperature of $293 \mathrm{~K}, \mathrm{CuK} \alpha$ radiation $(\lambda \alpha \mathrm{Cu}=1.5418$ $A$ ) when the counter speed $2 \mathrm{deg} / \mathrm{min}$ and feed 2400 $\mathrm{mm} / \mathrm{h}$.

\section{Experimental results and discussion}

Figure 1 shows the resulting relative elongation $\varepsilon$ depending on the applied stress $\sigma$ for non-irradiated metallized polyimide film.

It is seen that the metallization of polyimide film increases its elongation by $120 \%$ and breaking stress up to $\sim 175 \mathrm{MPa}$. This is due to the method of preparation of these films - the chemical etching of the metal (silver in our case). The surface layer morphology of metallized samples is nanostructured, but nonuniform in terms of the volume. It appeared as $50 \mathrm{~nm}$ metal-packed grains. The surface layer grains have a size of $8-10 \mathrm{~nm}$. There is a special gradient distribution of the metal in the film volume with a maximum concentration of metal on the outer layer, decreasing in accordance to depth.

Behavior of the material under mechanical deformation can be described by the following analytical expression showing dependency of $\varepsilon$ on $\sigma$ :

$$
\varepsilon=\exp \left(\frac{\sigma}{E}\right)^{-1}
$$

Expanding expression (1) into series we find that:

$$
\varepsilon=\frac{\sigma}{E}+\frac{\sigma^{2}}{2 ! E}+\frac{\sigma^{3}}{3 ! E}+\ldots \ldots
$$

where $\mathrm{E}$ is the average elasticity modulus of the composite material.

The first and second terms of the series (2) describe the behavior of the material in the elastic region. The first term describes the expansion behavior of the material during the deformation in the linear part (when $\sigma<35 \mathrm{MPa}$ ), i.e. Hooke's law, and the second term of the expansion - in a non-linear (if $\sigma$ $\geq 35 \mathrm{MPa}$ ). The third term takes into account the expansion behavior of the material in the plastic field for which the value of $E n$ is not a modulus of elasticity, etc.

In accordance to (2) we considered the dependence $\varepsilon=\mathrm{f}(\sigma)$ on unexposed metallized polyimide films in the elastic region, for which on the basis of experimental data the average elastic modulus of 31.7 MPa was determined. 
As can be seen in Figure 1, the experimental and theoretical curves matches very well until the area of loads $\sim 140 \mathrm{MPa}$. The further increase in load leads to an increase of plastic deformation of the composite material, which causes it to tear, and this process requires to consider the expansion of $\varepsilon=\mathrm{f}(\sigma)$ with subsequent members and parameters $E_{n}$.

$$
\varepsilon, \%
$$

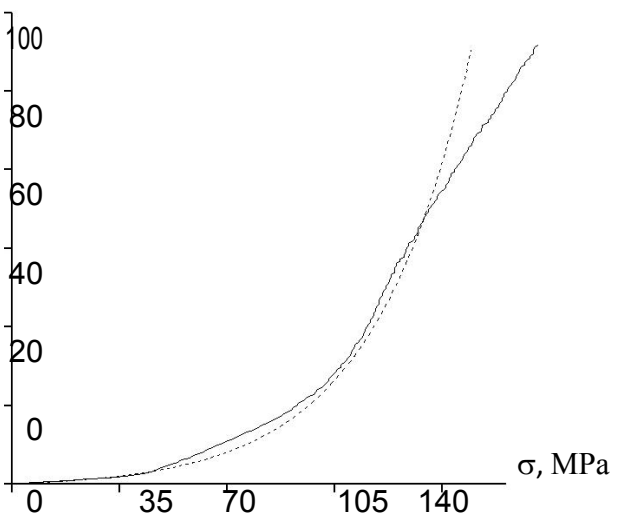

1- experiment; 2 - calsculations

Figure 1 - Change of the relative elongation $\varepsilon$ from applied stress $\sigma$ on nonirradiated metallized polyimide films

Figure $2(a, b)$ shows obtained dependencies of the relative elongation from the stress for irradiated metallized polyimide films.

Electron irradiation of the metallized film degrades its strength and elastic characteristics and elastic modulus is reduced depending on the dose of irradiation and is:

$$
\begin{gathered}
\text { given } \mathrm{D}=10 \mathrm{MGy}-E=31.1 \mathrm{MPa} \\
\begin{array}{c}
\mathrm{D}=20 \mathrm{MGy}-E=31 \mathrm{MPa} \\
\mathrm{D}=30 \mathrm{MGy}-E=30.1 \mathrm{MPa} \\
\mathrm{D}=40 \mathrm{MGy}-E=27 \mathrm{MPa}
\end{array}
\end{gathered}
$$

The impact of electron irradiation on the metallized polyimide films caused the following: in process of increase of the radiation dose maximum burst relative elongation decreases. Thereby, for a dose of 10 MGy it is about $100 \%$ and for 40 MGy, about $18 \%$; respectively, the material strength is decreased from 160 to $80 \mathrm{MPa}$ (Figure $2 \mathrm{a}, \mathrm{b}$ ).

The proposed mathematical model describes the dependence of the elastic region of the relative elongation from stress of the metallized film based on polyimide as well as irradiated by electrons (see. Figure $2 \mathrm{a}, \mathrm{b}$ ).

The study of the complex effects of temperature, static load ( $80 \%$ of the rupture) and electron irradiation on these materials showed that for nonirradiated films rupture relative elongation is $\sim 90 \%$, and the time from the beginning of the application of the load rupture -24 minutes. For films irradiated with dose of $40 \mathrm{MGy}-\varepsilon=30 \%$ и $\tau=8$ min., i.e. time of the load exposure on the material decreases threefold.

The electrical properties of the metallized film are also greatly impacted by a technology of production of polyimide, which leads, in particular, to a difference in surface structures on different sides of the film (glossy and matte). And it was established that the glossy side, among other things, has better optical properties than the matte, and matte has a smaller electrical resistivity.

The obtained radiographs show the changes in the structure of the material affected by electron irradiation and the effects of uniaxial mechanical stress (Fig. 3). It is evident that as a result of stretching and rupture of the unexposed film the intensity of the first peak (at about $\sim 16^{\circ}$ ) decreases by about 78 units offsetting in the direction of increasing by about $\sim 6^{\circ}$ and a similar effect on the irradiated film a dose of 40 MGy causes an additional decrease in the intensity of the maximum of 20 units same offset.

The first maximum of the curve 1 indicates that the initial material had a well ordered structure. Reducing of the intensity and shift of a peak towards increasing angles after the above mentioned influences on metallized film indicates that ordering structure is disturbed and ruptures of macromolecules of the polyimide occur. These changes of the peak lead to the the fact that as a result of Compton scattering on the new centers X-ray spectrum is shifted to larger angles $\left(\theta>70^{\circ}\right)$.

Occurrence and amplification of additional peaks at $\theta=25^{\circ}$ and $\theta=37^{\circ}$ indicates that as the result of these effects new phases with dielectric properties in the form of silver oxide are formed in the material. Amplification of these peaks is associated with the fact that electron irradiation of the metallized film causes growth of the new phase, which increases with irradiation dose. 


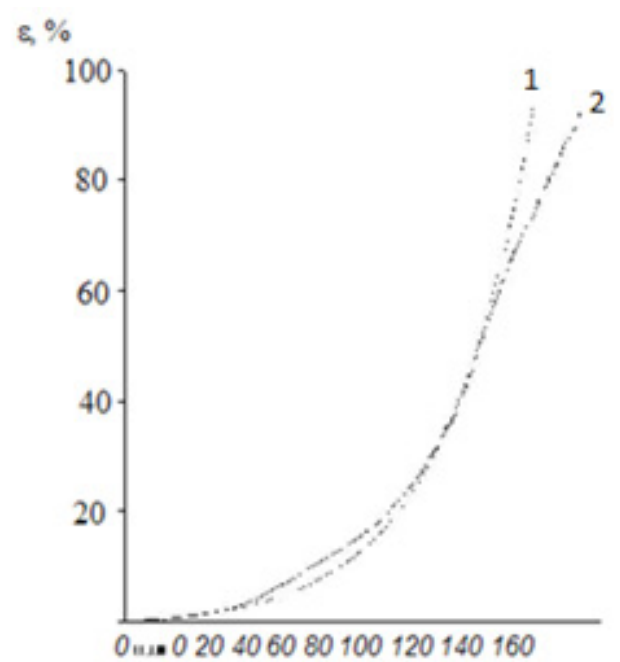

a) $\varepsilon, \%$

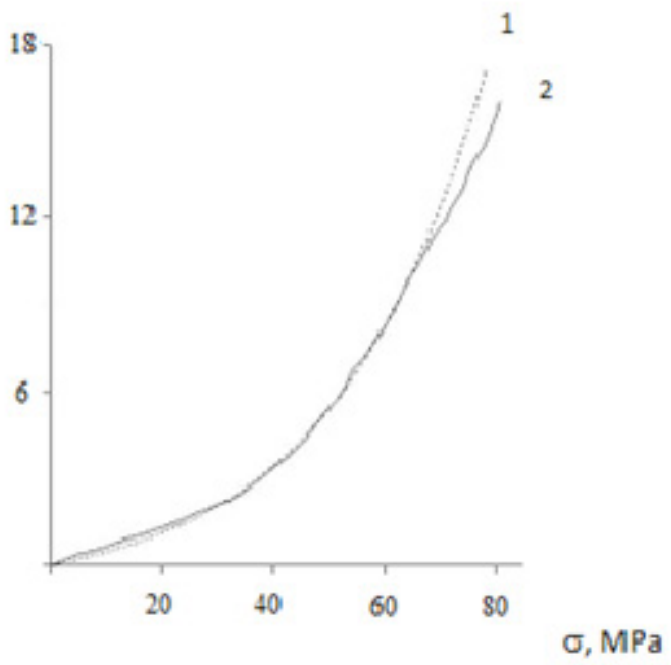

b)

1 - Experiment; 2 - Calculations
$\mathrm{D}=10 \mathrm{MGy}$ (a); $40 \mathrm{MGy}$ (b)

Figure 2 - Change in relative elongation of the applied load of metallized polyimide films, electron-irradiated with various doses D

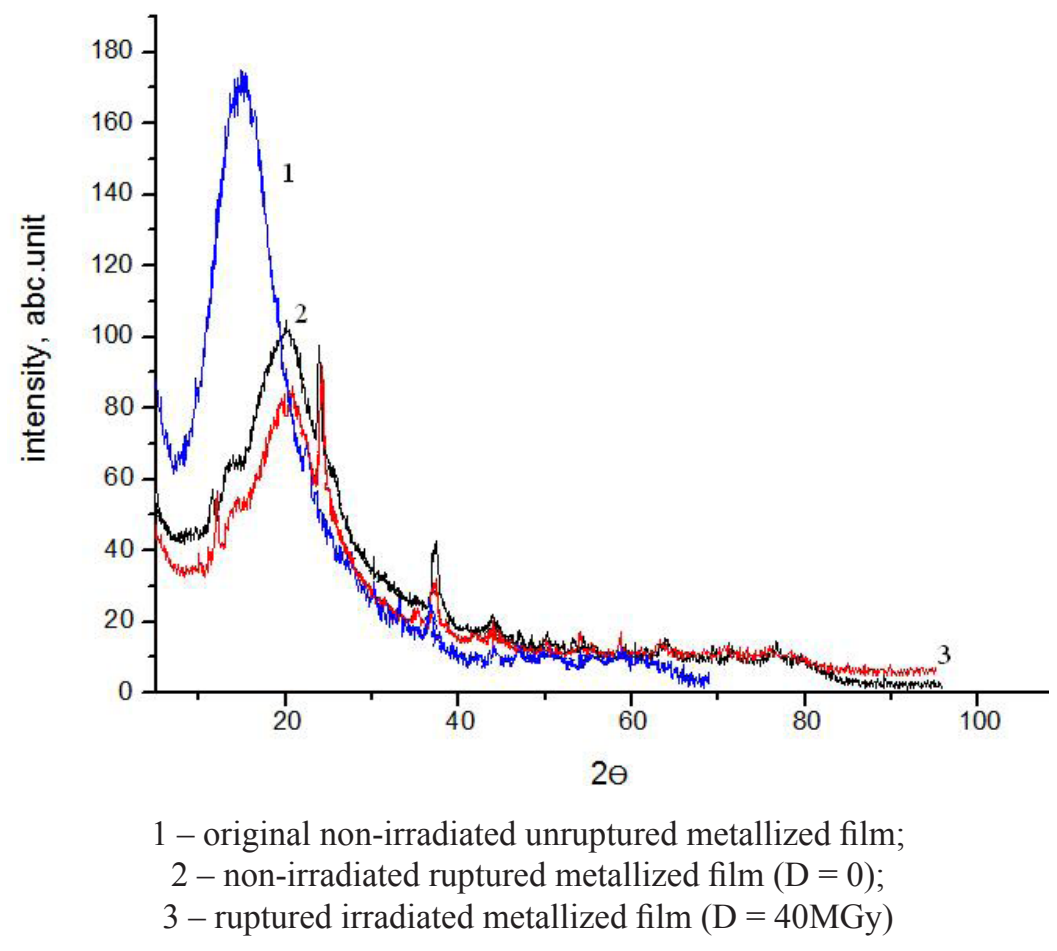

Figure 3 - Radiographs of composite materials based on a polymer 


\section{Conclusions}

It has been established that the metallization of the polyimide film increases the the relative elongation by up to $120 \%$, applied voltage reaches $175 \mathrm{MPa}$, which is associated with the peculiarities of the structure of these films and the conditions of chemical etching.

Increasing the dose of the electron irradiation results in a decrease in rupturing elongation and, respectively, to the reduction of material strength.

The degree of metallization of the film greatly affects the growth the electrical resistivity. Increasing the radiation dose for all types of of metallization samples leads to a significant increase in the surface electrical resistance of the film. However, films with low metallization will reach saturation of conductivity with increasing irradiation dose quicker, than films with a higher degree of metallization.

Electronic irradiation and uniaxial mechanical tension of metallized polyimide film disturbs the ordered structure of the material, in the form of breaking the links of macromolecules and the formation of new phases.

Proposed mathematical model describes the behavior of the metallized polyimide films in the elastic region under the influence of uniaxial mechanical loading on films, which were nonirradiated, as well as electron-irradiated with various doses.

\section{References}

1. Ch.-J. Huang, Ch.-Ch. Yen, T.-Ch. Chang. Studies on the preparation and properties of conductive polymers. III. Metallized polymer films by retroplating out // Journal of Applied Polymer Science. -1991. -Vol. 43. - No. 8. - P. 2237 2245.

2. H. Nino, A. Yabe. Excimer laser polymer ablation: formation of positively charged surfaces and its application into the metallization of polymer films // Applied Surface Science -1993. -Vol. 69.-No.1-4. -P.1-6.

3. B. Walgenwitz, J.-H. Tortai, N. Bonifaci, A. Denat. Self-healing of metallized polymer films of different nature // Proceedings of the 2004 IEEE International Conference on Solid Dielectrics, 5-9 July 2004, Toulouse, France. -2004. - P.1-4.

4. X. Wang, T. Zhang, B. Kobe, W. M. Laud, J. Yang. Grafting of polyelectrolytes onto hydrocarbon surfaces by high-energy hydrogen induced cross-linking for making metallized polymer films // Chem. Commun. -2013. -Vol.49. P. 4658-4660.

5. S.C. Domenech, E. Lima Jr., V. Drago, J.C. De Lima, N.G. Borges Jr., A.O. V. Avila, V. Soldi. Electroless plating of nickel-phosphorous on surface-modified poly(ethylene terephthalate) films // Applied Surface Science. - 2003. -Vol. 220. -No. 1-4. -P. 238-250.

6. H. Pagès, P. Topart, D. Lemordant. Wide band electrochromic displays based on thin conducting polymer films // Electrochimica Acta. - 2001. -Vol. 46. -No. 13-14. -P. 2137-2143.

7. M. Makdessi, A. Sari, P. Venet. Metallized polymer film capacitors ageing law based on capacitance degradation // Microelectronics Reliability. -2014. -Vol. 54. -No. 9-10. -P. 1823-1827M.

8. J. Hillenbrand, G. M. Sessler. High-sensitivity piezoelectric microphones based on stacked cellular polymer films (L) // The Journal of the Acoustical Society of America. -2004. -Vol. 116. -P. 3267.

9. A. I. Kupchishin, B. G. Taipova, A. A. Kupchishin, B. A. Kozhamkulov. Study on the physical and mechanical properties of composites based on polyimide and polycarbonate // Mechanics of Composite Materials. - 2015. - Vol. 51. -No.1. -P. 115-118.

10. H.-J. Ni, J.-G. Liu, Zh.-He Wang, Shi-Yo.Yang. A review on colorless and optically transparent polyimide films: Chemistry, process and engineering applications // Journal of Industrial and Engineering Chemistry. - 2015. Vol.28. -P.16-27.

11. J. Gong, Zh. Liu, J.Yu, D. Dai, W. Dai, Sh. Du, Ch. Li, N. Jiang, Zh. Zhan, Ch.-T. Lin. Graphene woven fabricreinforced polyimide films with enhanced and anisotropic thermal conductivity // Composites Part A: Applied Science and Manufacturing. - 2016. -Vol. 87. -P. 290-296.

12. J.Xia, T.-Sh. Chung, D.R .Paul. Physical aging and carbon dioxide plasticization of thin polyimide films in mixed gas permeation // Journal of Membrane Science. - 2014. - Vol. 450. - P. 457-468.

13. Y. Zhao, Q. Lu, D. Chen, Y. Wei. Superhydrophobic modification of polyimide films based on gold-coated porous silver nanostructures and self-assembled monolayers // J. Mater. Chem. - 2006. - Vol.16. - P. 4504-4509.

14. D.-J. Liaw, F.-Ch. Chang, M. Leung, M.-Y. Chou, K. Muellen. High thermal stability and rigid rod of novel organosoluble polyimides and polyamides based on bulky and noncoplanar naphthalene-biphenyldiamine // Macromolecules. - 2005. - Vol. 38 (9). -P. 4024-4029. 
15. T. Agag, T. Koga, T. Takeichi. Studies on thermal and mechanical properties of polyimide-clay nanocomposites // Polymer. -2001. -Vol. 42. -No. 8. -P. 3399-3408.

16. Sh.-H. Xie, B.-K. Zhu, X.-Zh. Wei, Zh.-K. Xu, Y.-Yi Xu. Polyimide/BaTiO 3 composites with controllable dielectric properties // Composites Part A: Applied Science and Manufacturing. -2005. -Vol.36. -No.8. - P.1152-1157.

17. X.Wei, Sh. Hong, L. Xiao, Sh.Yan, R.Qia, N.Yao, T.Li. Fabrication and properties of polyimide composites filled with zirconium tungsten phosphate of negative thermal expansion // Materials Chemistry and Physics. - 2016. Vol. 179. - P. 72-79.

18. R. Cooper, D. Ferguson, D. P. Engelhart, R. Hoffmann. Effects of radiation damage on polyimide resistivity // Journal of Spacecraft and Rockets. -2017. -Vol. 54. -No. 2. -P. 343-348.

19. A. Makovec, G. Berruti, M. Consales, M. Giordano, P. Petagna, S. Buontempo, G. Breglio, Z. Szillasi, N. Benig, A. Cusano. Radiation hard polyimide-coated FBG optical sensors for relative humidity monitoring in the CMS experiment at CERN // Journal of Instrumentation. -2014. -Vol. 9. -P. 1-10.

20. S.A. Nouh, M.J. Tommalieh, N.T. El-Shamy. Structural and optical modifications in gamma-irradiated polyimide/ silica nanocomposite // Radiation Effects and Defects in Solids, Incorporating Plasma Science and Plasma Technology. -2015. -Vol. 170. - No.6. -P. 548-555. 